\title{
A mídia na Ciência da Informação
}

\author{
Information Science and the media
}

\author{
César Antonio PEREIRA' (iD) 0000-0001-7620-7874
}

\section{Resumo}

As transformações no campo midiático, impulsionadas pelas Tecnologias de Informação e Comunicação, advindas de procedimentos técnicos e de linguagem, possibilitaram o aumento do fluxo de informação bem como sua visibilidade e circulação na sociedade. Fundamentalmente, a ocupação do campo midiático nas sociedades contemporâneas tornou-se estratégica. Apesar disso, permanece pouco conhecida a relação do campo da Ciência da Informação com a temática. Assim, este artigo busca compreender as bases teóricas e empíricas dos estudos sobre mídia na Ciência da Informação. De maneira específica, procurou-se identificar os comportamentos temporal e temático dos estudos sobre mídia na Ciência da Informação. Constitui-se em estudo bibliométrico e cientométrico de caráter exploratório com abordagem quali-quantitativa. O universo da pesquisa é composto pela produção científica sobre mídia, presente nos artigos da área indexados na Web of Science. Para a compreensão dos objetos dos estudos identificados, utilizou-se análise de conteúdo. Os resultados permitem traçar o perfil do comportamento temporal e temático dos estudos desenvolvidos, situando o período de publicação, as respectivas áreas de conhecimento correlacionadas à Ciência da Informação e os assuntos de maior ocorrência. Dada a complexidade que a temática requer, vislumbra-se maior aprofundamento epistemológico e pragmático para futuras produções.

Palavras-chave: Bibliometria. Ciência da Informação. Cientometria. Mídia. Mídia social.

\begin{abstract}
The transformations in the field of media, driven by Information and Communication Technology, deriving from technical procedures and language, have facilitated an increase in the flow of information, as well as its visibility and circulation in society. Most importantly, the media have become strategic in contemporary societies. In spite of this, the relation between the field of Information science and the subject remains little known. Thus, this article seeks to understand the theoretical and empirical foundations of media studies in Information Science. In particular, our focus was to identify the temporal and thematic behaviors of studies concerning the media in Information Science. It is an exploratory study of the bibliometrics and scientometrics with a quali-quantitative approach. The research universe was composed of scientific production on media in articles related to the area indexed in the Web of Science. Content analysis was used to understand the objects of the studies identified. The results enabled us to map the profile of the temporal and thematic behavior of the studies, locate the period of publication, areas of knowledge with production that are related to Information Science, and the most frequent issues addressed. Given the complexity of the topic, a more profound epistemological and pragmatic approach is envisioned for future production.
\end{abstract}

Keywords: Bibliometric studies. Information Sciences. Scientometric studies. Media. Social media.

\footnotetext{
1 Pontifícia Universidade Católica de Campinas, Centro de Linguagem e Comunicação, Programa de Pós-Graduação em Linguagens, Mídia e Arte. R. Professor Doutor Euryclides de Jesus Zerbini, 1.516, Parque Rural Fazenda Santa Cândida, 13087-571, Campinas, SP, Brasil. E-mail: <cesarpereira@puc-campinas.edu.br>. Recebido em 19 de julho de 2017, versão final aprovada em 14 de agosto de 2017.
}

Como citar este artigo/How to cite this article

Pereira, C. A. A mídia na Ciência da Informação. Transinformação, v. 30, n. 2, p. 141-152, 2018. http://dx.doi.org/10.1590/2318-08892018000200001 


\section{Introdução}

Nas últimas décadas, várias transformações socioeconômicas impulsionaram alterações nas demandas produtivas de bens e serviços na sociedade. De modo concomitante, as transformações no campo midiático, impulsionadas pelas Tecnologias de Informação e Comunicação (TIC), advindas de procedimentos técnicos e de linguagem, possibilitaram o aumento do fluxo de informação bem como sua visibilidade e circulação na sociedade. A ocupação do campo midiático nas sociedades contemporâneas tornou-se estratégica.

O campo midiático, segundo Rodrigues (1990), pode ser compreendido como uma indicação do estado institucional de mediação que se observa na atualidade. Os dispositivos midiáticos, formal ou informalmente organizados, são abarcados pelo campo midiático, com a função de representar os valores legítimos das instituições. Logo, ao campo midiático é atribuído valor preponderante, pois exerce forte influência em diversificados processos.

A estrutura, principalmente ao redor das redes de comunicação midiática, tem o poder de atingir uma ampla gama de receptores, fazer visíveis os processos, mobilizar a opinião pública e negociar as demandas com os diversos e diferentes campos e atores constituintes da sociedade, assumindo ou colocando-se na condição e posição de mediador desses processos, no fenômeno da midiatização. Por sua vez, a midiatização configura-se como um processo de interação e negociação que se dá pelas relações com e através da mídia. Como sujeito, como elemento que dá e faz a ação, a mídia expõe e faz o exposto, medeia e se faz mediador (Steffen, 2013).

A aparição da Web 2.0, estrutura centrada na participação dos usuários, atribuiu grande importância à mídia, especialmente a mídia social. Centrada no desenvolvimento de aplicações e websites, permitiu aos usuários criar, difundir e compartilhar conteúdos. Basicamente, uma nova configuração, um modelo de colaboração e interação que permite novos formatos de produção, organização e uso de informação. Especificamente, não só permite que "muitos outros" comentem as informações publicadas e com elas colaborem, mas também permite que os usuários gerenciem os próprios conteúdos (Briggs, 2007). Agora, busca-se atender a um usuário de informação que reclama imediatamente e possui maior participação no processo informativo. Trata-se de um usuário que contribui na produção de conteúdos informativos. Não se conforma apenas com seu consumo (Levinson, 2012), mas é coautor do mesmo (Renó, 2011).

Nesse modelo de comunicação midiático é necessário contar que a informação é interativa, pois permite a participação direta e imediata; é personalizada, porque é possível a seleção ativa de conteúdos; é documentada, graças ao hipertexto e às relações; está atualizada, porque as notícias se publicam enquanto se produzem, fazendo alterar o conceito de periodicidade; integra todos os formatos de produção: texto, áudio, vídeo, gráficos, fotos, em um só meio, que é multimídia; pode aplicar processos que se executam em ordem e requerem uma nova concepção do desenho que, muito mais que estético, deve, sobretudo, facilitar ao leitor a navegação (Barbosa, 2007).

Como assinala Díaz-Noci (2009), nos novos suportes digitais tanto o produto multimídia como as estratégias de leitura são dinâmicos, e as páginas Web são representações e construções da informação que o leitor, mediante sua ativa intervenção, recupera de uma determinada forma servindo-se de uma interface. O leitor desenvolve estratégias de leitura com a recuperação, a busca, a exploração ou a divagação, e espera com a busca da informação estabelecer um diálogo com outros textos, abrangendo, assim, da hipertextualidade à intertextualidade (Pena-Fernández; Lazkano-Arrillaga; Gárcia-González, 2016).

Logo, a adaptação dos meios de comunicação tradicionais aos novos suportes digitais e sua interface, tem contribuído para uma paulatina transformação dos próprios meios e suas audiências. Isso propicia profundas mudanças no panorama dos meios de comunicação, que abarcam desde a produção de conteúdos até as mudanças na rotina de trabalho, os suportes e as estratégias de distribuição e modelos de negócio (Casero-Ripollés, 
2012). Para Jenkins (2009), essas estruturas têm contribuído com a criação do que denomina como uma "cultura de convergência", em que se tem diluído a larga separação entre os criadores de conteúdos e suas audiências.

Assim, o raciocínio central apoiado em Thompson (1998), é de que os meios de comunicação midiáticos não servem apenas para comunicar informação aos indivíduos. Eles condicionam e regulam novos formatos e estratégias de interação e ação informacional na sociedade, plasmando novos relacionamentos sociais, quer dos sujeitos com o mundo, quer dos sujeitos consigo próprios.

Apesar da relevância das reflexões sobre mi-diatização e sobre usos e usuários da informação, permanece pouco conhecida a relação do campo da Ciência da Informação (CI) com a temática, sobretudo, com a mídia e com as estruturas e estratégias informacionais adotadas na sociedade contemporânea. Pouco se conhece sobre como a informação é investigada, sobre sua relação e aspectos de propriedade com outros campos e áreas do conhecimento, ou sobre quais temas e objetos teóricos têm norteado os estudos acerca da temática. Como um campo do conhecimento que examina os processos de comunicação e fluxo de informação para a construção de conhecimento, vislumbra-se na Cl grande amparo epistemológico e pragmático para investigar estudos sobre mídia, visando reduzir as incertezas e auxiliar na compreensão dos aspectos produtivos e estruturais do conhecimento nas mais diversas camadas sociais.

Busca-se, portanto, compreender as bases teóricas e empíricas dos estudos sobre mídia na $\mathrm{Cl}$, buscando contribuir com as reflexões científicas. Objetiva-se, de maneira específica, identificar os comportamentos temporal e temático dos estudos sobre mídia na $\mathrm{Cl}$.

A análise da pesquisa praticada sobre mídia na Cl condiciona o conhecimento dos mecanismos sociais e intelectuais dos estudos desenvolvidos. A compreensão do panorama atualizado do uso desses estudos possibilita buscar caminhos para o aprimoramento e incorporação de alternativas que possibilitem complementá-los com informações dos contextos cognitivos e sociais da atividade científica nas diversas áreas de conhecimento. Por outro lado, possibilita potencializar as contribuições dos estudos sobre midiatização, ao evidenciar não apenas o que é e o que acontece, mas também o que poderia ser, uma vez que a pesquisa se propõe a traçar o panorama do uso desses estudos nos diferentes campos do conhecimento bem como as bases teóricas e empíricas que orientam tais estudos e os focos temáticos.

Logo, é esperado que o presente estudo possa contribuir para o debate sobre as limitações atuais e perspectivas para aplicação e busca de alternativas que possibilitem melhor qualificação das discussões no ambiente acadêmico. Com o panorama dos estudos sobre mídia espera-se contribuir para uma reflexão crítica que leve ao aperfeiçoamento de tais estudos e a condições mais adequadas de gerenciamento administrativo e práticas de pesquisa e, por outro lado, melhor qualidade da informação para subsidiar a elaboração de políticas científicas e de informação para diferentes campos do conhecimento.

Finalmente, o entendimento do contexto em que os estudos sobre mídia se inserem na Cl permite não apenas quantificar a produção, mas também possibilitar a compreensão epistemológica, histórica e social desse campo.

\section{Procedimentos metodológicos}

Trata-se de pesquisa de caráter exploratório de abordagem quali-quantitativa. Foram adotados procedimentos bibliométricos e cientométricos para a análise dos dados. O corpus de análise é constituído por artigos científicos publicados em periódicos indexados na base Web of Science na área da Ciência da Informação (Information Science and Library Science). A busca dos artigos foi realizada seguindo algumas etapas indicadas por Lopes (2002). Foram utilizadas palavras-chave traduzidas para o idioma inglês: "mídia"; "ciência da informação". Houve realização de busca a partir da lógica booleana (palavras combinadas por AND e OR) e/ou operadores de truncagem (palavras 
combinadas por "?" ou "*", utilizados para recuperar palavras a partir dos prefixos ou sufixos). Foi considerado todo o período temporal coberto pela base.

Visando identificar os aspectos temporal e temático que pudessem subsidiar a compreensão dos estudos produzidos sobre mídia no âmbito da Cl, foi realizada análise de conteúdo dos estudos (Bardin, 1977) para a demarcação dos domínios de conhecimento e objetos teóricos abordados.

Finalmente, os dados colhidos foram organizados e mensurados a partir dos Estudos Métricos da Informação, especificamente pelas especialidades bibliometria e cientometria. Utilizou-se, para tanto, o software Bibexcel para a extração e mensuração dos dados. Para a representação gráfica dos resultados, utilizaram-se os programas Microsoft Excel e Ucinet/Netdraw.

\section{Resultados e Discussão}

Foram encontrados 4.498 estudos sobre mídia na Ciência da Informação indexados na base Web of Science. O recorte temporal da produção analisada está distribuído em 32 anos (1985-2016). A distribuição é marcada por acentuada representatividade do número de estudos publicados (Figura 1).

Os primeiros nove estudos datam da década de 1980, especificamente do ano de 1985. Nesse período, a produção científica vinculada à temática das mídias na Cl não apresenta grande representatividade produtiva, muito embora possua relevância temática para essa área. Somada a década de 1990, verifica-se crescimento linear dos estudos: entre 1985-1999 foram identificados 752 estudos, o que representa 16\% do total publicado ao longo desses 32 anos.

Nos últimos anos, observa-se crescimento exponencial do número de trabalhos publicados sobre a temática. Entre 2000-2009, foram identificados 1.232 estudos, com representação de 29\% do total de anos identificados.

A década de 2010 é marcada por significativa ascensão do número de trabalhos publicados. No período 2010-2016, foram publicados 2.514 estudos, 1.282 a mais que no período anterior, o que representa 55\% dos

144

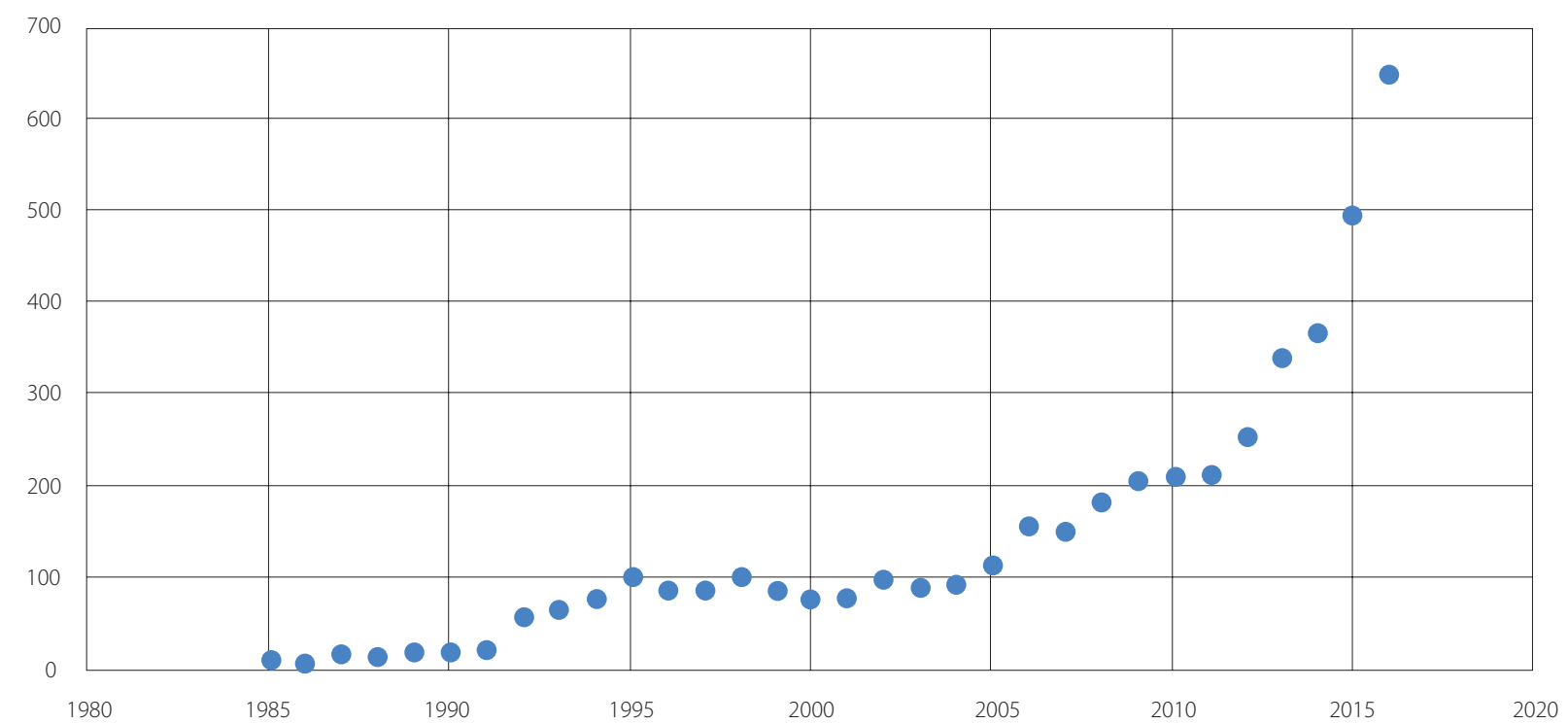

Figura 1. Evolução temporal dos estudos sobre mídia publicados na base Web of Science (1985-2016) na área da Ciência da Informação. Fonte: Elaborada pelo autor (2017). 
estudos publicados sobre a temática. Verifica-se intenso crescimento ano a ano, demarcando o período como o mais significativo do total de publicações identificadas ao logo dos anos. Especificamente, os anos de 2015 e 2016 - com 492 e 648 estudos publicados, respectivamente -, representam cerca de 45\% do total produzido na década e $25 \%$ do período pesquisado.

Ao longo do período analisado, foram identificadas, além da Ciência da Informação, outras 19 áreas de pesquisa com concentração quantitativa de estudos publicados sobre mídia, correlacionados à Cl (Tabela 1).

No caso dos domínios do conhecimento dos trabalhos publicados, observou-se relação do campo da Cl com outros campos em 3.157 estudos, ou 70,00\% do total. Logo, o campo da Ciência da Informação publicou 30,00\% do total de estudos sobre mídia sem qualquer relação com as demais áreas. Do total de 19 áreas com correção produtiva de estudos sobre mídia na Cl, destacam-se: "Computer Science", com 33,33\% de correlação, representada em 1.499 estudos publicados; "Communication", com 629 estudos; "Business Economics", com 436 estudos; e "Social Sciences - other topics", com 207 estudos publicados. A correlação identificada entre essas áreas com a Cl representa $61,00 \%$ do total de estudos sobre mídia. Somados aos estudos desenvolvidos apenas pela Cl, verifica-se que 91,00\% dos estudos sobre mídia estão compreendidos por essas áreas de conhecimento. Outras 15 áreas de conhecimento possuem baixa correlação com a Cl, representando apenas 9,00\% do total de estudos identificados.

A análise dos objetos de pesquisa permitiu a observação de que os primeiros estudos sobre mídia na Cl visavam comparar a credibilidade das informações promovidas pelo uso das "mídias de massa" em relação às

Tabela 1. Áreas do conhecimento correlacionadas à Ciência da Informação, com estudos sobre mídia publicados na base Web of Science (1985-2016).

\begin{tabular}{|c|c|c|}
\hline Áreas de Pesquisa & Estudos & $\%$ \\
\hline Computer Science & 1.499 & 33,33 \\
\hline Communication & 629 & 13,98 \\
\hline Business \& Economics & 436 & 9,69 \\
\hline Social Sciences - Other Topics & 207 & 4,60 \\
\hline Telecommunications & 74 & 1,65 \\
\hline Medical Informatics & 51 & 1,13 \\
\hline Geography & 44 & 0,98 \\
\hline Biomedical Social Sciences & 41 & 0,91 \\
\hline Physical Geography & 41 & 0,91 \\
\hline Education \& Educational Research & 29 & 0,64 \\
\hline Arts \& Humanities - Other Topics & 22 & 0,49 \\
\hline Health Care Sciences \& Services & 20 & 0,44 \\
\hline Philosophy & 19 & 0,42 \\
\hline History & 15 & 0,33 \\
\hline Science \& Technology - Other Topics & 14 & 0,31 \\
\hline Social Issues & 9 & 0,20 \\
\hline Government \& Law & 5 & 0,11 \\
\hline History \& Philosophy of Science & 1 & 0,02 \\
\hline Women's Studies & 1 & 0,02 \\
\hline Total & & $70,00^{*}$ \\
\hline Information Science \& Library Science & 4.498 & 100,00 \\
\hline
\end{tabular}

Nota: "70,00: O cálculo se refere ao total percentual de estudos desenvolvidos em outras áreas que não a Ciência da Informação. A linha abaixo do total é apenas um indicador para comparação com os dados acima (70\%).

Fonte: Elaborada pelo autor (2017). 
informações disponibilizadas por bibliotecas e unidades de informação, de maneira especial, as públicas. Para tanto, eram entrevistados cidadãos, usuários de bibliotecas e bibliotecários de modo a compreender o perfil de suas necessidades informacionais.

Ao longo dos anos, outros estudos apresentavam reflexões sobre as competências a serem desenvolvidas em bibliotecas e unidades de informação à luz das novas mídias, em especial aquelas relacionadas ao suporte digital. Atribui-se ainda, necessidade de novas competências aos profissionais da informação. A aplicação dos meios digitais informacionais em escolas e universidades, modelos de aprendizado e novas tecnologias de organização e gestão de acervos também conduziu a atenção dos estudos.

As pesquisas sobre mídia na área da Cl têm-se desenvolvido à luz da compreensão teórica sobre o objeto informação bem como sobre seu fluxo e uso a partir dos diversificados suportes midiáticos digitais e eletrônicos, advindos do uso intensivo da Internet e da Web. Substancialmente, o conceito de mídia (meio) observado em muitos dos estudos relacionados à área, apresenta análises condicionadas ao impacto das mídias digitais e eletrônicas sobre a produção, divulgação, transmissão e uso de informação: livros digitais e eletrônicos, formatos de representação e descrição da informação digital, hiperlinks, busca e recuperação da informação, digitalização de acervos informacionais, gestão e coleção de mídias (CD, DVD, entre outros), multimídia e reflexões sobre o futuro das unidades de informação, entre outros.

Não obstante, estudos mais recentes passaram a desenvolver reflexões sobre a "mídia social" e, de maneira mais acentuada, configuraram-se como os mais frequentes. As relações sociais estabelecidas por plataformas, modelos e dispositivos tecnológicos apresentam grande preocupação no campo da Cl. A disseminação da informação e a compreensão das necessidades e aperfeiçoamento das competências, visando novos modelos de gestão de coleções, unidades de informação e relacionamento com usuários, tornaram-se a tônica de muitos estudos. Cabe o destaque aos modelos métricos da informação, especialmente no que tange à análise do impacto das mídias digitais na publicação científica e, mais recente, àqueles condicionados aos modelos alternativos de avaliação da ciência e de sua produção, como os estudos altmétricos.

A correlação da $\mathrm{Cl}$ e demais áreas de conhecimento na produção de estudos sobre a temática ao longo dos anos, é identificada como fator preponderante. Compreender os impactos e interferências da mídia na assimilação da informação requer, além dos estudos sociais e das relações que se processam entre sujeitos, maior apropriação das tecnologias, recursos e softwares desenvolvidos e aplicados na organização, estratificação, coleta, análise, transmissão e conteúdo das mensagens e das informações. Isso, sobretudo, porque os processos de disseminação da informação ocorrem nos mais variados contextos - formais e informais, científicos ou não-científicos -, e, assim, devem promover o uso contextualizado. Tal reflexo tem sido abordado há tempos pela $\mathrm{Cl}$ a partir de autores como Barreto $(1998,1999)$, na medida em que evidencia que o fluxo da informação por meio de uma estrutura mais dinâmica, fundamentada no instrumental tecnológico, passou a atuar basicamente numa maior interação entre o gerador e o receptor. Tanto a interação quanto o tempo e a estrutura da informação, com a utilização das novas tecnologias, imprimem maior velocidade e novas estruturas no acesso ao conhecimento.

Para tanto, torna-se fundamental estudar o sentido da informação não somente a partir de sua natureza, estrutura e registros, como também a partir da comunicação e recursos empregados, incluindo características como novidade, relevância, percepções simbólicas dotadas de significado e questões individuais (Capurro; Hjørland, 2003). Ainda, são levados em conta não só os processos de transmissão da informação, mas também as possibilidades semânticas, hermenêuticas e pragmáticas propiciadas pela seleção e interpretação da informação pelos sujeitos.

Por outro lado, a compreensão das estruturas matemáticas, administrativas, de negócios e de comunicação (que regulam e estabelecem o cenário da informação à luz da mídia) também encontra amparo na $\mathrm{Cl}$, em especial quando correlacionada às áreas de "Business \& Economics" e "Communication". As reflexões contemporâneas quanto ao uso estratégico e tecnológico da informação em variados cenários econômicos, políticos e de gestão, condi- 


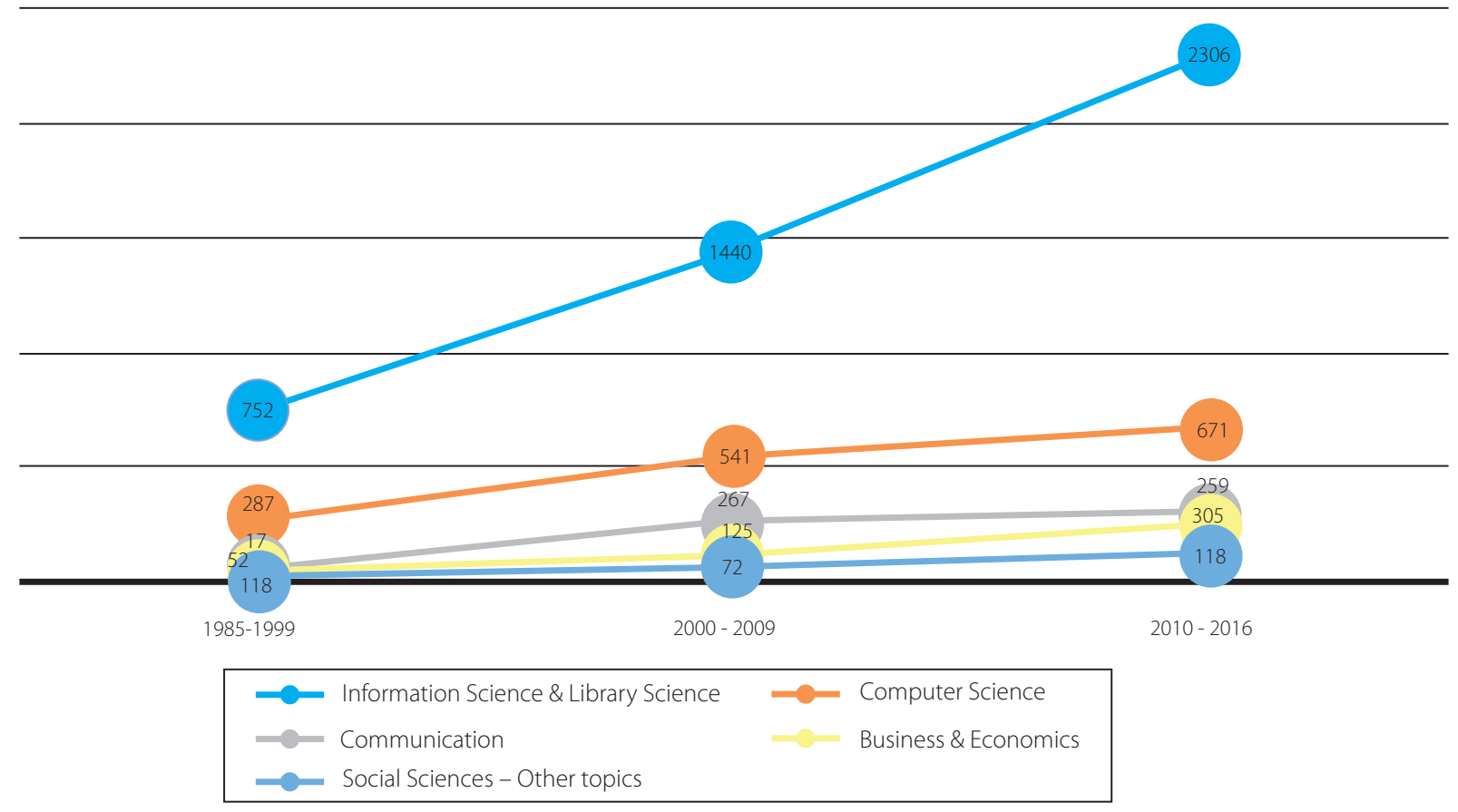

Figura 2. Crescimento dos estudos sobre mídia por áreas do conhecimento correlacionadas à Cl, publicados na base Web of Science (1985-2016).

Fonte: Elaborada pelo autor (2017).

cionam novos formatos de consumo de informação e de comportamentos informacionais e comunicacionais dos usuários. Sobre isso, cresce o número de estudos desenvolvidos em gestão da informação e do conhecimento.

À medida que essas discussões foram aper-feiçoadas e refletidas visando compreender os aspectos teóricos e práticos sobre a temática, foram também se alterando as correlações entre a área de Ciência da Informação e as de Ciência da Computação, Comunicação, Economia e Negócios e Ciências Sociais (Figura 2).

Ao observar o aumento dos estudos sobre mídia nas áreas do conhecimento com maior representatividade, constata-se que esse crescimento está praticamente equacionado até o final da década de 2000. A partir da década de 2010 dobrou o número de estudos sobre mídia publicados na área de Cl. Embora haja crescimento dos estudos correlacionados com as demais áreas, a taxa de crescimento pela Cl segue em ritmo exponencial.

Assim, a correlação entre a $\mathrm{Cl}$ e as demais áreas, presente nos estudos sobre mídia iniciados na década de 1980, passa a apresentar nova configuração à medida que aquela área avança na produção científica sobre a temática, em especial nos últimos anos. Acredita-se, portanto, que as reflexões sobre mídia, sua natureza, estrutura, transmissão e significado tenham encontrado conforto na Cl.

A atribuição da qualidade dos estudos publicados é outro fator preponderante na área. Foram identificados 188 títulos de periódicos com publicações sobre mídia na área da Cl. Grande destaque são os periódicos "Journal of Health Communication", "Journal of Computer-Mediated Communication", "Social Science Computer Review", "Online Information Review", "Aslib Proceedings" e, ainda, "Profesional de la Información", "Electronic Library", "Government Information Quarterly" e "Telematics and Informatics", com 31\% de representatividade no total de publicações sobre a temática. Os cinco primeiros periódicos mencionados contêm estudos sobre mídia correlacionados com Ciência da Informação, Ciência da Computação e Comunicação, ao passo que as três revistas seguintes apresentam apenas estudos no campo da Cl. Já outros títulos de periódicos, como "Information \& Management", publicaram estudos 
correlacionados entre Cl e "Business \& Economics". Do total de títulos identificados com estudos produzidos sobre a temática, 63\% se situavam no campo apenas da Cl. Do total de títulos identificados com estudos produzidos sobre a temática, $63 \%$ publicaram estudos sobre mídia cobertos apenas pela $\mathrm{Cl}$.

Todos os periódicos com produção relacionada a mídia na Cl possuem grande relevância qualitativa no cenário mundial. Tal constatação deve-se, a rigor, pelos procedimentos adotados pela Web of Science (WoS), fonte de dados do presente estudo. A WoS seleciona continuamente, a cada duas semanas, as revistas. Além disso, a cobertura de títulos existentes passa por constante revisão, de maneira a assegurar que eles obtenham grande relevância para a comunidade cientííca. Todas as revistas são analisadas quali e quantitativamente. Os dados das revistas são correlacionados e inter-relacionados, possibilitando assegurar ao editor o conforto do estabelecimento dos pontos fortes e fracos da publicação (Testa, 1998).

Em razão dessa conjuntura, a WoS é reconhecida com uma fonte que disponibiliza alta qualidade de informação no campo científico e tecnológico, uma vez que o rigor da avaliação das revistas indexadas imputa tal característica. Soma-se a isso a utilização da base, em especial do fornecimento dos dados das publicações, para o monitoramento das informações científicas e tecnológicas visando o estabelecimento de políticas de informação e de ciência e tecnologia, como no caso do Brasil.

O reflexo dessa estrutura desencadeia qualidade nas temáticas abordadas nos estudos e alta credibilidade nos processos de organização da informação. Como resultado, torna-se uma expressiva fonte de informação para a compreensão dos domínios de conhecimento.

Dentre as temáticas desenvolvidas na área da $\mathrm{Cl}$, observadas a partir das palavras-chave e da análise de conteúdo, destacam-se aquelas relacionadas à compreensão do impacto das relações informacionais estabelecidas pela mídia, sobretudo pela mídia social, bem como as temáticas relacionadas às tecnologias e plataformas de comunicação midiática e aos impactos dessa estrutura em ambientes e unidades informacionais (Figura 3).

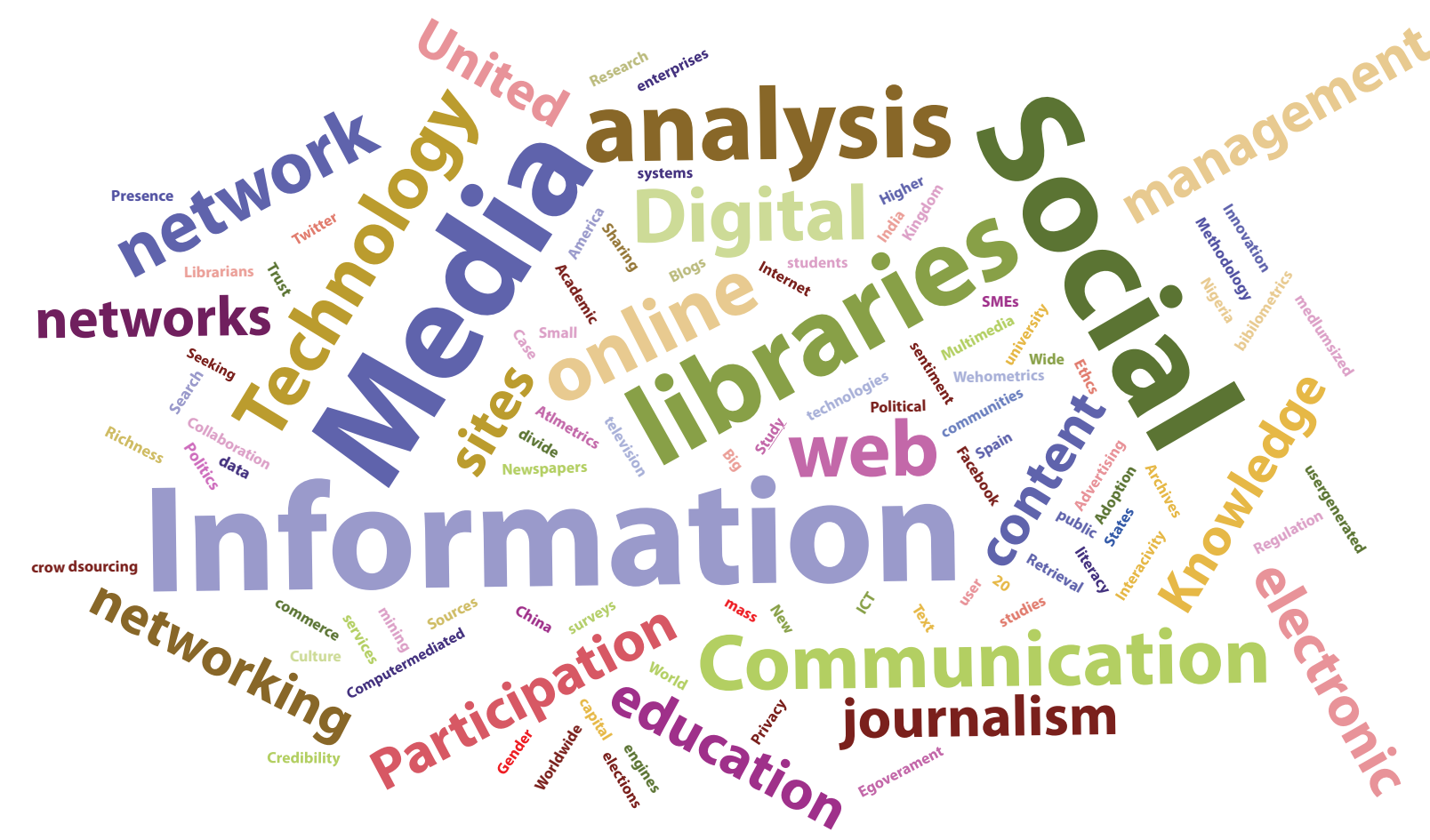

Figura 3. Palavras-chave utilizadas em estudos sobre mídia na Cl, publicados na base Web of Science (1985-2016). Fonte: Elaborada pelo autor (2017). 
Do total de 7.598 palavras-chave distribuídas entre 4.498 estudos sobre mídia na Cl, 10\% evidenciam-se como as mais proeminentes: "Social Media,", Internet", "Twitter", "Electronic Media," "Web 2.0", "Facebook", "Knowledge Management", "Social Networks", "Media", "Academic Libraries", "Information Retrieval", "China" e "Communication". Cada uma dessas palavras-chave foi utilizada, no mínimo, entre 40 e 470 estudos publicados nos anos mais recentes.

Os termos "Social Media" e "Internet" destacam-se entre todos os demais, pois representam 4,5\% do total de termos identificados. Dos 470 estudos representados pelo termo "Social Media", em 195 deles há correlação com o termo "Internet". A aplicação desses termos em 665 estudos retrata, dentre outros aspectos: objetos condicionados ao uso das mídias sociais em publicações cientíicas buscadas por ferramentas e análise de dados; aprendizado dos processos de busca de informações em mídias sociais; impacto da mídia (conteúdo, mobilidade, interatividade e multimedialidade) para o estabelecimento de políticas informacionais; uso das mídias sociais como estratégia para obtenção de fundos e recursos para unidades de informação; organização política a partir das mídias sociais; impacto das mídias sociais sobre o comportamento informacional de adolescentes; uso das mídias sociais por agências governamentais; emprego das mídias sociais georreferenciadas como informação geográfica; análise automática de textos em mídias sociais e na Internet; previsão eleitoral baseada em Big Data e Business Intelligence de informações provenientes de mídias sociais; participação e envolvimento das redes sociais dentro das organizações.

Outros termos, como "Twitter" e "Facebook", com representação de 1\% do total, configuram-se com dualidade de objetos de pesquisa. Em primeiro momento, são entendidos como plataformas de relacionamento social e de acesso e produção de mensagens/informações entre os sujeitos e a sociedade, proporcionando acesso aos dados desses relacionamentos, com vistas à compreensão das estruturas sociais. Permitem a participação democrática e contextualizada, além de análise dos conteúdos das mensagens e compreensão das relações entre sujeitos. Por outro lado, também são compreendidos como objetos norteadores dos próprios relacionamentos, ferramentas essenciais ao desenvolvimento humano e comunicacional, fruto do modelo de colaboração social. Em essência, é a própria representação dos sujeitos e da estrutura social. Há, ainda, estudos que os utilizam visando não só à inserção dos sujeitos na sociedade, mas também, como ferramentas de aperfeiçoamento educacional, científico e estratégico, seja para os negócios, seja para as unidades de informação. Ainda, observam-se estudos de uso do "Twitter" e do "Facebook" relacionados a: mídia de comunicação de crise; dados georreferenciados gerados pelos usuários para gestão de analistas espaciais; aplicação de altmetria e cientometria para a compreensão dos fluxos informacionais; método de análise para governança digital em cidades inteligentes; ou, ainda, estudo das características da propagação de notícias.

Estudos com temáticas relacionadas a "Information Literacy" e "Information Management" também foram identificados. Nesses casos, destacam-se objetos circunscritos a: investigar as capacidades de alfabetização informacional de policiais a partir das mídias sociais; evidenciar hábitos informacionais de estudantes em novos meios digitais para mostrar o futuro potencial de livros eletrônicos; avaliar a qualidade da informação em saúde na Internet; investigar os sistemas de gestão do conhecimento a partir das mídias sociais; analisar a agenda de mídia sobre assuntos municipais, com base em gestão política e administrativa.

Relacionados especificamente ao ambiente de unidades de informação, vislumbram-se os seguintes termos: "Academic Libraries", "Information Retrieval", "Libraries" e "Digital Libraries". Os estudos condicionados a eles apresentam aplicações variadas: descrição de blog institucional com o objetivo de promover a leitura da população universitária; mineração de textos para um conjunto de dados significativos de tweets para bibliotecas acadêmicas; mensuração de mídias sociais para bibliotecas universitárias; velocidade de pesquisa em blogs; inferência de localização de usuários de unidades de informação a partir do Twitter; descrição de recursos eletrônicos para a mediação da informação; futuro das unidades de informação no ecossistema das mídias sociais; sistemas para desenvolvimento e publicação de documentos digitais; tecnologias para recuperação e acesso online a coleções de vídeos digitais; promoção de bibliotecas digitais a partir de campanhas de mídia social; repositórios institucionais e mídias sociais; estratégias de construção e manutenção de bibliotecas digitais. 
Correlacionados por área de conhecimento, observa-se forte impacto desses termos na representação quantitativa das principais áreas com produção científica sobre a temática (Figura 4).

Embora amplamente abordados na área da Ciência da Informação, verifica-se correlação entre os domínios de conhecimento no que tange às reflexões sobre as principais palavras-chave identificadas nos estudos sobre mídia. As discussões sobre "Social Media" provocadas pela Cl encontram amparo de correlação em 36,0\% com a área da Ciência da Computação, 16,5\% com a área de Negócios e Economia, 8,0\% com a área de Ciências Sociais e 7,0\% com a área da Comunicação.

Em todos os demais relacionamentos temáticos, observa-se a mesma ordem de posição de correlação entre áreas. A Cl, resguardada a especificidade do presente trabalho, correlaciona-se em um primeiro momento com a Ciência da Computação, Negócios e Economia, Ciências Sociais e Comunicação. Portanto, a Ciência da Computação é a área com maior grau de correlação na produção de estudos sobre mídia na Ciência da Informação. Em essência, nesses estudos, quando correlacionados à Ciência da Computação, são elencadas as estruturas tecnológicas que promovem o acesso, comunicação e uso de informação midiática. Já na área de Negócios e Economia, verificam-se estudos constituídos de plataformas de contato com consumidores de produtos eletroeletrônicos, tanto para compartilhar e construir conhecimento, quanto para aumentar a visibilidade de produtos e serviços a partir das mídias. Em Ciências Sociais, os estudos são conduzidos pelas reflexões sobre a mídia social, sua interação e integração na vida, permitindo a compreensão dos relacionamentos das organizações humanas. Na Comunicação,

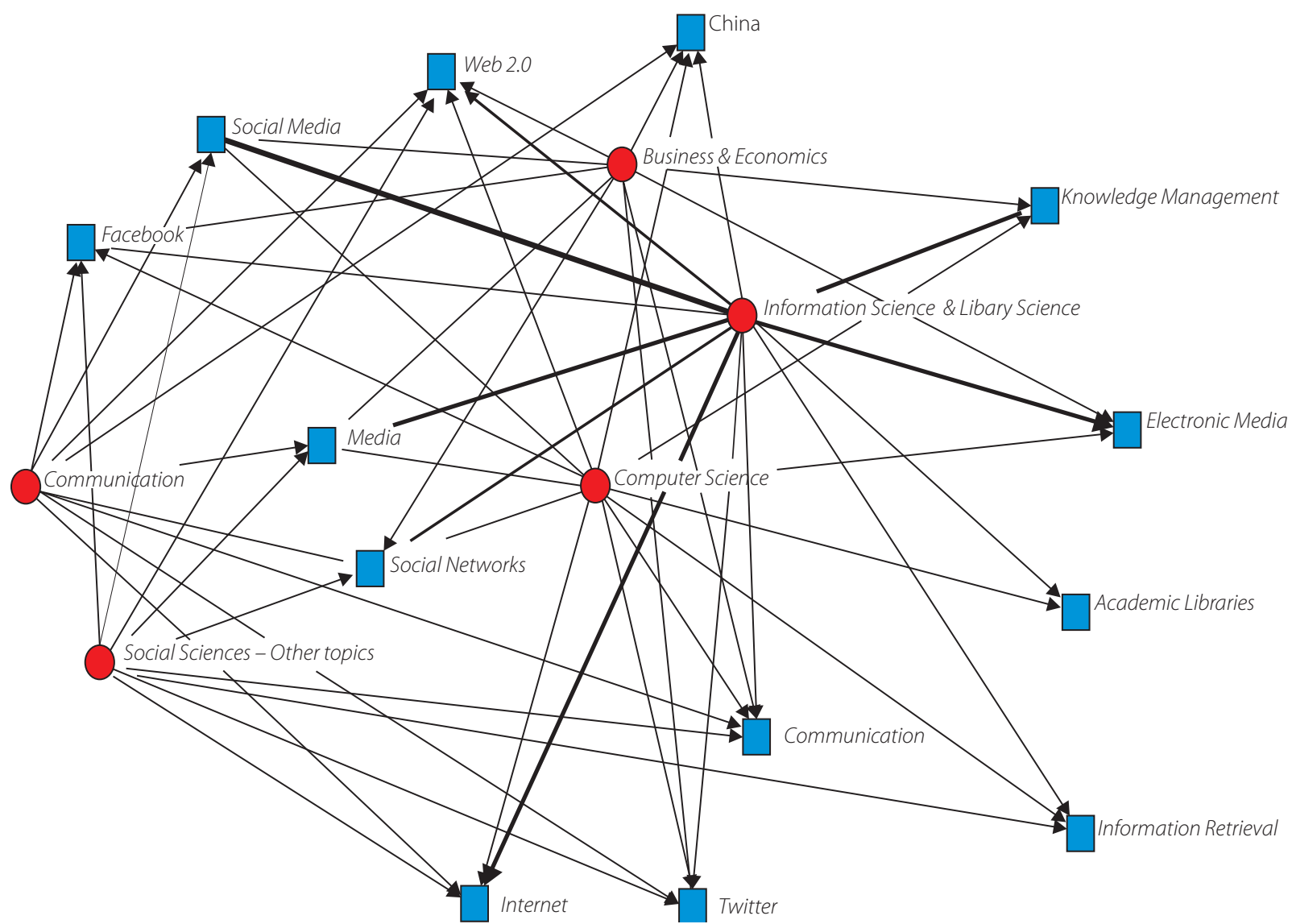

Figura 4. Correlação das palavras-chave e áreas de pesquisa em estudos sobre mídia na Cl, publicados na base Web of Science (1985-2016). Fonte: Elaborada pelo autor (2017). 
os estudos recaem sobre ativismo político, práticas de transformação comunicacional e compreensão das funções comunicativas de microblogs para as organizações sociais.

Demais estruturas e domínios de conhecimento correlacionados à Cl proporcionam reflexões contextualizadas aos aspectos de relação e rede, mensagem, mídias digitais, informação, usos e usuários de informação. Seja para a manutenção ou aperfeiçoamento dos negócios baseados em informação e seu gerenciamento, seja para a compreensão das estruturas sociais e comunicacionais da mensagem e seu significado, parece ser a correlação entre essas áreas a tônica dos estudos sobre mídia na Cl.

À medida que os estudos sobre mídia tomam proporções quantitativas significativas, a Cl vê-se envolvida em questões acerca dos impactos e interferências da mídia digital e eletrônica na assimilação da informação disseminada pelos sujeitos - como também se vê compelida a compreender os modelos de mediação da informação, por meio de plataformas de colaboração social. Evidencia-se, portanto, atenção aos formatos de uso, comportamento e usuários de informação, visando não só ao aperfeiçoamento dos modelos de gestão da informação e das unidades de informação, mas também à melhoria dos negócios, produtos e serviços informacionais.

\section{Conclusão}

A análise da ciência praticada mostra que os estudos sobre mídia na Cl se constituem com alta produtividade, como indicador para estudos com diferentes finalidades, evidenciados a partir do tempo e da quantidade de estudos bem como das temáticas envolvidas.

Os estudos sobre mídia na área da Cl têm-se desenvolvido à luz da compreensão teórica sobre o objeto informação, registro, fluxo e uso, a partir dos diversificados suportes midiáticos digitais e eletrônicos, advindos do uso intensivo da Internet e da Web. Substancialmente, o conceito de mídia observado em muitos dos estudos relacionados apresenta análises condicionadas ao impacto das mídias digitais e eletrônicas na produção, divulgação, disseminação e uso da informação. Não obstante, estudos sobre "Mídia Social" também se configuram como os mais frequentes.

O campo da Cl, correlacionado a outros campos do conhecimento, sobretudo nos estudos de produção, disseminação e uso da mídia social, orienta a prática científica. O reconhecimento do papel das mídias digitais e eletrônicas, assim como as nuances de suas aplicações e representações nos contextos de produção, representação e divulgação da informação, assume relevância significativa no contexto contemporâneo. A interação entre diversos componentes no processo de criação do conhecimento, em especial a partir de plataformas de relacionamento social, resulta numa constante criação de informação e conhecimento, investimentos centrais para o aumento de aprendizado e inovação. O campo da Cl parece acompanhar essa tendência. Nos últimos anos, observa-se um crescimento exponencial do número de trabalhos publicados sobre a temática, refletindo a variedade de tópicos de estudos abordados.

No entanto, dada a complexidade que a temática requer, vislumbra-se maior aprofundamento epistemológico e pragmático para futuras produções sobre a mídia na Cl.

\section{Referências}

Barbosa, S. Jornalismo digital de terceira geração. Covilhã: Universidade da Beira Interior, 2007.

Bardin, L. Análise de conteúdo. Lisboa: Edições 70, 1977.

Barreto, A. A. Mudança estrutural no fluxo do conhecimento: a comunicação eletrônica. Ciência da Informação, v. 27, n. 2, p. 122-127, 1998. 
Capurro, R.; Hjørland, B. The concept of information. Annual Review of Information Science and Technology, v. 37, n. 8, 2003.

Available from: <http://www.capurro.de/infoconcept.html>. Cited: Apr. 23, 2006

Casero-Ripollés, A. Más allá de los diários: el consumo de noticias de los jóvenes en la era digital. Comunicar, v. 20, n. 39, p. 151-158, 2012.

Díaz-Noci, J. Multimedia y modalidades de lectura: una aproximacíon al estado de la cuestión. Comunicar, v. 17, n. 33, p. 213-219, 2009.

Jenkins, H. Cultura da convergência. 2. ed. São Paulo: Aleph, 2009.

Levinson, P. New Media. Boston: Pearson Higher Education, 2012.

Lopes, I. L. Estratégia de busca na recuperação da informação: revisão da literatura. Ciência da Informação, v. 31, n. 2, p. 60-71, 2002.
Pena-Fernández, S.; Lazkano-Arrillaga, I.; Gárcia-González, D. La transición digital de los diários europeus: nuevos produtos y nuevas audiências. Comunicar, v. 24, n. 46, p. 27-36, 2016.

Renó, D. Cinema interativo e linguagens audiovisuais interativas: como produzir. Tenerife: Editorial ULL, 2011.

Rodrigues, A. D. Estratégias da comunicação: questão comunicacional e formas de sociabilidade. Lisboa: Presença, 1990.

Steffen, C. O surgimento da midiocracia. Em Questão, v. 19, n. 1, p. 258-274, 2013.

Testa, J. A base de dados ISI e seu processo de seleção de revistas. Ciência da Informação, v. 27, n. 2, p. 233-235, 1998.

Thompson, J. B. A mídia e a modernidade: uma teoria social da mídia. Petrópolis: Vozes, 1998. 